\title{
Understanding Relational Dysfunction in Borderline, Narcissistic, and Antisocial Personality Disorders: Clinical Considerations, Presentation of Three Case Studies, and Implications for Therapeutic Intervention
}

\author{
Genziana Lay \\ Private Psychotherapy Practice, Sassari, Italy
}

\begin{abstract}
Personality disorders are a class of mental disorders involving enduring maladaptive patterns of behaving, thinking, and feeling which profoundly affect functioning, inner experience, and relationships. This work focuses on three Cluster B personality disorders (PDs) (Borderline, Narcissistic, and Antisocial PDs), specifically illustrating how relational dysfunction manifests in each condition. People with Borderline Personality Disorder (BPD) experience pervasive instability in mood, behavior, self-image, and interpersonal patterns. In relationships, they tend to alternate between extremes of over-idealization and devaluation. Intense fear of abandonment, fluctuating affect, inappropriate anger, and black/white thinking deeply influence how they navigate personal relationships, which are often unstable, chaotic, dramatic, and ultimately destructive. They have a fundamental incapacity to self-soothe the explosive emotional states they experience as they oscillate between fears of engulfment and abandonment. This leads to unpredictable, harmful, impulsive behavior and chronic feelings of insecurity, worthlessness, shame, and emptiness. Their relationships are explosive, marked by hostility/contempt for self and partner alternating with bottomless neediness. Manipulation, lying, blaming, raging, and "push-pull" patterns are common features. Individuals with Narcissistic Personality Disorder (NPD) exhibit a long-standing pattern of grandiosity and lack of empathy. They have an exaggerated sense of self-importance, are self-absorbed, feel entitled, and tend to seek attention. Scarcely concerned with others' feelings, they can be both charming and exploitative. Oversensitive to criticism, they are prone to overt or covert rage, gaslighting and self-referential thinking. Antisocial Personality Disorder (APD) is marked by impulsive, callous, and irresponsible behavior with no regard to be manipulative, parasitic, aggressive, cold, cruel, and self-serving. In addition to analyzing relational dysfunction in each disorder, this paper presents three relational case studies (BPD-couple, NPD-parent/child, APD-various relations) and discusses treatment implications.
\end{abstract}

Keywords: dysfunction, personality disorders, Cluster B, borderline, narcissistic, antisocial, relationships

\section{Introduction}

Personality disorders (PDs) are a class of mental disorders involving enduring maladaptive patterns of behaving, thinking, and feeling which profoundly affect functioning, inner experience, and relationships. These

Genziana Lay, Dr., Private Psychotherapy Practice, Sassari, Italy. 
patterns are usually evident by late adolescence, remain stable over time, and generate psychological distress. There is typically impairment in personality functioning in the areas of identity, self-direction empathy, and intimacy. In the DSM-V, pathological personality traits are organized into five trait domains: negative affectivity, detachment, antagonism, disinhibition, and psychoticism, each of which is further illustrated with trait facets reflecting aspects of the domain itself. This trait system has been shown to correlate well with the Five Factor Model (Oldham, 2015).

There are 10 different personality disorders grouped into three clusters based on descriptive resemblances within each cluster. Cluster A is the odd, eccentric cluster and includes Paranoid Personality Disorder, Schizoid Personality Disorder, and Schizotypal Personality Disorders. The common features of these are social awkwardness, social withdrawal, and distorted or delusional thinking. Cluster B is called the dramatic, emotional, and erratic cluster and includes Borderline Personality Disorder, Narcissistic Personality Disorder, Histrionic Personality Disorder, and Antisocial Personality Disorder. The common denominator among these is a pattern of problems with impulse control, relationships, and emotional regulation. Cluster $\mathrm{C}$ is called the anxious, fearful cluster. It includes the Avoidant, Dependent, and Obsessive-Compulsive Personality Disorders. These three personality disorders share a high level of anxiety and rigidity.

Because personality disorders are, by definition, pervasive and influence perception, behavior, thinking, and emotional processing, they inevitably have a profound effect on the person's close relationships. This work focuses on three Cluster B personality disorders (Borderline, Narcissistic, and Antisocial Personality Disorder), specifically illustrating how relational dysfunction manifests in each condition. People with Borderline Personality Disorder (BPD) experience pervasive instability in mood, behavior, self-image, and interpersonal patterns. In relationships, they tend to alternate between extremes of over-idealization and devaluation. Intense fear of abandonment, fluctuating affect, inappropriate anger, and black/white thinking deeply influence how they navigate personal relationships, which are often unstable, chaotic, dramatic, and ultimately destructive. They have a fundamental incapacity to self-soothe the explosive emotional states they experience as they oscillate between fears of engulfment and abandonment. This leads to unpredictable, harmful, impulsive behavior and chronic feelings of insecurity, worthlessness, shame, and emptiness. Their relationships are explosive, marked by hostility/contempt for self and partner alternating with bottomless neediness. Manipulation, lying, blaming, raging, and "push-pull" patterns are common features. Individuals with Narcissistic Personality Disorder (NPD) exhibit a long-standing pattern of grandiosity and lack of empathy. They have an exaggerated sense of self-importance, are self-absorbed, feel entitled, and tend to seek attention. Scarcely concerned with others' feelings, they can be both charming and exploitative. Oversensitive to criticism, they are prone to overt or covert rage, gaslighting and self-referential thinking. Antisocial Personality Disorder (APD) is marked by impulsive, callous, and irresponsible behavior with no regard to be manipulative, parasitic, aggressive, cold, cruel, and self-serving.

In addition to analyzing relational dysfunction in each disorder, this paper presents three relational case studies. Case 1 examines the dysfunctional relational pattern experienced by a couple with one partner suffering from Borderline Personality Disorder. Case 2 examines the maladaptive, distressing characteristics of the relationship between a mother with Narcissistic Personality Disorder and her daughter and the lasting effects on the child as she grows into adulthood. Case 3 illustrates the pathological features of relatedness with family, intimate partners and society at large expressed by a young man with Antisocial Personality Disorder. Treatment implications are discussed for each. 


\section{Personality Disorders: Conceptualization and Diagnostic Framework}

As defined in the alternative model presented in the DSM-V, personality functioning is assessed by considering the degree to which there is an intact sense of self (clear, coherent identity and effective self-directedness) and healthy interpersonal functioning (capacity for relatedness, empathy, and intimacy) (Oldham, 2015). The hallmark features of personality disorders are distorted thinking patterns, problematic emotional responses, over or under-regulated impulse control, and persistent interpersonal difficulties.

Broadly speaking, three domains can be considered when clinically evaluating personality disorders. As outlined in Otto Kernberg's model, these relate to reality testing, sense of self and defenses (Hoermann, Zupanick, \& Dombeck, 2018). The first thing to be considered is whether the person has intact reality testing - essentially assessing their capacity to distinguish between real and imagined, as well as between internal and external. When reality testing is impaired, the person will find it challenging to separate real events occurring around him or her from subjective perceptions. Obvious examples of this include hallucinations, delusions, and severely distorted emotional/cognitive processing. A person suffering from Paranoid Personality Disorder, for example, will develop a mental framework of beliefs and perceptions in line with a distorted, personal sense of reality that is usually menacing, persecutory, and bizarre.

The second consideration concerns an integrated sense of self and others. The foundations for this are set in childhood through interaction with significant others. If they are largely functional and core emotional needs are met, the child builds an inner blueprint of him/herself and others, as well as of how healthy relationships operate, that is adaptive and healthy. However, when the building blocks for this are marked by dysfunction, deprivation, and/or disruption, the child may develop a fragile, volatile, contradictory, and maladaptive sense of self, others and relationships. With an integrated sense of self, one is able to distinguish between self and others, and accurately perceive personal characteristics and differentiate personal perceptions, feelings, and thoughts from those of others. Moreover, one can understand and tolerate having contradictory feelings and beliefs about the same person. For example, it is possible to be angry and know someone is angry at you without feeling any love or respect in that relationship has vanished and will result in permanent change (abandonment, hostility, etc.) - an essential premise for any healthy relationship. In contrast, a fragmented sense of self leads one to confusing, highly distressing relational experiences wherein conflict, disappointment, or even self-doubt can destroy any sense of security or emotional continuity and subjective feelings become blurred with real interactions. For example, this is commonly observed in people with Borderline Personality Disorder who experience splitting and have extreme reactions to any perceived sense of abandonment.

The third consideration has to do with the person's defenses and whether they are predominantly mature or primitive (Hoermann, Zupanick, \& Dombeck, 2018). Defenses are simply strategies (often unconsciously enacted) people use to manage internal conflict between competing feelings, fears, impulses, and urges and to cope with emotional demands and stressful circumstances. Primitive defenses, conceptually, are the psychodynamic counterpart of maladaptive coping mechanisms; mature defenses are akin to healthy coping strategies. A person enacting primitive defenses may try to rearrange reality or ignore social demands in a disorganized effort to self-soothe that only leads to more distress and relational dysfunction. In contrast, someone who can count on more mature defenses is more adaptable and psychologically solid when confronted with distressing stimuli. For example, a person with Narcissistic Personality Disorder may tend to relate to others as split-off projections of their fluctuating sense of self (from grandiose to deeply precarious), 
manipulating them and attempting to conform reality to their inner experience. Children of Narcissists may in fact feel a blurred distinction between self and caregiver in the sense that their own perceptions and needs are distorted through the lens of the dysfunctional parent's constant overwriting of their experience for their own benefit.

A categorical diagnostic system for personality disorders has some shortcomings. For example, in the DSM-IV the threshold required to make a diagnosis was arbitrary, yet the impression was conveyed that overall a given disorder is either present or it is not, rather than conceptualizing it as a symptom and trait pattern with varying gradients of severity (Oldham, 2015). Inclusion in a category involves satisfying in each case one-half plus one of a group of diagnostic criteria; this is known as polythetic assessment (Esbec \& Echeburúa, 2015). A downside of this system is that it generates a marked level of heterogeneity within similar diagnoses. For example, there are 256 ways that five out of nine criteria for the diagnosis of borderline personality disorder can be configured, and two patients could receive this diagnosis but share only one criterion (Oldham, 2015).

While the APA Board of Trustees voted to sustain the DSM-IV diagnostic system for personality disorders in the main section, the DSM-5 also includes an alternate new model in Section III referred to as "Emerging measures and models". In this conceptualization, essential criteria to define any personality disorder are significant impairment in personality functioning and pathological personality traits (Oldham, 2015). A "level of functioning" scale is indicated and, based on research data, "moderate impairment" is identified as the appropriate threshold to indicate the presence of a personality disorder (Oldham, 2015). A new diagnosis called Personality Disorder-Trait Specified was also established in the DSM-V, replacing Personality Disorder Not Otherwise Specified in DSM-IV. This diagnosis indicates that a patient meets the general criteria for a personality disorder and has a pathological trait profile that can include characteristics of different disorders and trait facets (Oldham, 2015). In this conceptualization, the DSM-V covers other specified and unspecified personality disorders with mixed personality characteristics and other PDs not included in standard classification (for example, depressive PD or psychotic/sadistic PD) (Esbec \& Echeburúa, 2015).

Personality characteristics and patterns reminiscent of diagnostic criteria for PDs without significant distress and impairment can be considered personality style and not a full expression of the disorder. As defined in the alternative model, personality functioning consists of the degree to which there is an intact sense of self (coherent identity and effective self-directedness) and adaptive interpersonal functioning (with capacity for empathy and intimacy). Pathological personality traits are organized into five trait domains (negative affectivity, detachment, antagonism, disinhibition, and psychoticism), each of which is further explicated by a set of trait facets reflecting aspects of the domain itself.

This trait system has been shown to correlate well with the Five Factor Model (Oldham, 2015; Thomas, Yalch, Krueger, Wright, Markon, \& Hopwood, 2012).

Some theorists have pointed out that the extreme expressions of neuroticism, extraversion, openness, agreeableness, and conscientiousness on both the high and low ends are associated with characteristics of personality disorders (Trull \& Widiger, 2013). 
Table 1

Higher Order Domains and Corresponding Personality Trait Facets

\begin{tabular}{|l|l|}
\hline Higher order domain & Personality trait facets \\
\hline Negative affectivity & $\begin{array}{l}\text { Emotional lability, anxiousness, separation insecurity, submission, hostility, } \\
\text { perseverance, depressivity, suspiciousness, restricted affectivity }\end{array}$ \\
\hline Detachment & $\begin{array}{l}\text { Social withdrawal, avoidance of intimacy, anhedonia, depressivity, restricted } \\
\text { affectivity, suspiciousness }\end{array}$ \\
\hline Antagonism & Manipulativeness, deceitfulness, grandiosity, attention seeking, callousness, hostility \\
\hline Disinhibition & Irresponsibility, impulsivity, distractibility, risk taking, lack of exacting standards \\
\hline Psychoticism & Odd beliefs and experiences, eccentricity, cognitive and perceptual dysregulation \\
\hline
\end{tabular}

Sources: Esbec \& Echeburúa, 2015.

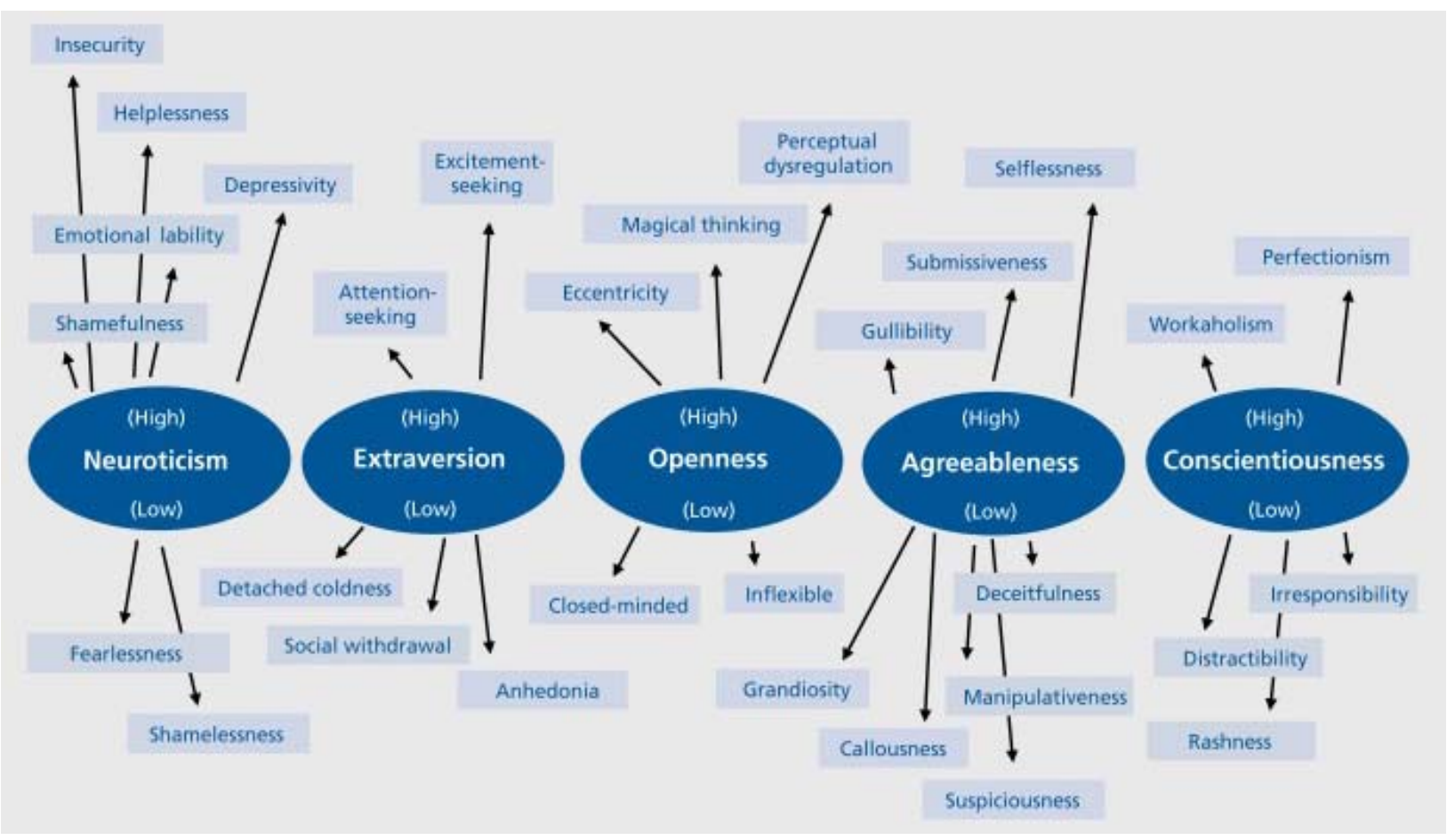

Figure 1. Traits and behaviors associated with 5 major personality dimensions (Trull \& Widiger, 2013).

Based on this conceptualization, one might hypothesize that an individual with antisocial personality disorder exhibits low levels of neuroticism, agreeableness, and conscientiousness; likewise, it could be posited that someone with borderline personality disorder displays high extraversion and high neuroticism.

\section{Borderline Personality Disorder}

Borderline Personality Disorder involves a pervasive pattern of instability in self-image, emotions, and interpersonal relationships as well as elevated impulsivity beginning by early adulthood and manifested in a variety of contexts. As outlined in the DSM, not all possible features of the disorders are always present concurrently, but different combinations therein concur to create a constellation of unstable, volatile symptoms which cause intense distress and disrupt relationships.

People with Borderline Personality Disorder tend to have intense yet unstable interpersonal relationships: They are deeply concerned with real or imagined abandonment. They fluctuate between extremes of idealization 
and devaluation. Their sense of self tends to be equally unstable. Lack of integration of the concept of self and others leads to identity diffusion and primitive defenses centering around splitting and its derivatives (projective identification, denial, primitive idealization, omnipotence, omnipotent control, devaluation) (Kernberg, 2001).

Reactions to daily life are marked by emotional instability and volatile feelings: Intense anger, episodic sadness, and overwhelming anxiety are common. Impulsive behavior, often including self-harming or self-damaging behavior, is frequent; it is not unusual for this to take the form of addiction to substances, sex, food, or thrill-seeking. Borderlines frequently are plagued by chronic feelings of emptiness and have a higher rate of suicidal behavior than average. In the relational sphere, which is arguably the most affected with borderline personality disorder, there is a tendency to form relationships quickly and intensely. Because of paradoxical instability (Sperry, 1995), a fluctuation between clinging/idealization and devaluation/abandonment terror instances; relationships are emotionally volatile and often explosive. These individuals seem to shift back and forth from hope to despair, blaming others for internal turmoil and experiencing a sense of lack of control of both intrapsychic states and outside circumstances. A sensitivity to rejection is so intense that even a slight stressor can lead to abandonment depression; being alone and frustration are scarcely tolerated, and social adaptiveness is superficial. There is a marked external locus of control and difficulty learning from past experience. During times of perceived intense stress, manifestations of paranoid ideation, dissociation, and micro-psychotic episodes may be present.

Behaviorally, borderlines are prone to dramatic or self-harming gestures, including suicide attempts and self-damaging behavior (addictions to substances, sex, food, etc., as well as provocation of conflict, risk-taking, and self-injury). Having difficulty with self-soothing and stability, irregularities in the sleep wake cycle common. It has been argued that they have underdeveloped evocative memory so that they have trouble recalling images and feeling - states to soothe them during turmoil (Sperry, 1995), leading to hyperbolic reactions characterized by a loss of emotional control and outward projection of rage and despair.

Borderline personality disorder is associated with an inflexible, impulsive cognitive style with rigid abstractions (Sperry, 1995), leading patients to view others in an idealized yet dichotomous manner (all good or all bad) depending on internal interpretations of external circumstances. As is typical with personality disorders, there is no healthy integrated sense of self. People with BPD have a diffused sense of identity and experience a blurring of lines between inner states and traits and other people's feelings and intentions. A fragmentation of self leads to confusion about boundaries, preferences, and self-directedness.

\section{Antisocial Personality Disorder}

An individual with Antisocial Personality Disorder usually exhibits an early-onset, pervasive pattern of lack of regard for rules and well-being of others. Instead, they are driven by self-gratification fueled by a sense of superiority, which often amounts to predatory behavior. There is a remarkable lack of capacity for remorse, real intimate bonding or true empathy. The person may indeed have a cognitive capacity to understand what others are feeling, but in APD this is known as "cold empathy" because it is not accompanied by appropriate emotions, but rather used as material for more effective manipulation of people and situations. To these individuals, life is a game, they are masters above the rules, and others are means to an end- vulnerable, weak, and justifiably prey. An antisocial personality disordered individual operates in what has been termed as a presocialized emotional world, wherein feelings are experienced in relation to the self but not to others and 
capacity to experience feeling states like reciprocal pleasure, gratitude, empathy, sympathy, affection, guilt, or remorse that require whole object relations. Emotional life is dominated by feelings of anger, sensitivities to shame or humiliation, envy, boredom, contempt, exhilaration, and pleasure through dominance (sadism) (Gabbard, 2014). Clearly there are different gradients of severity, but at the core, this is the foundation of the antisocial personality.

From a behavioral standpoint, people with APD tend to be impulsive, irritable, and aggressive - though this is sometimes hidden beneath a mask of self-serving self-control and moderated by the need for manipulation, which sometimes requires long-term planning. There is often a history of rule-breaking, unwillingness to honor commitments. They often exhibit thrill-seeking and competitive behavior, with a reckless disregard for safety and for the needs of others. Skilled liars, they are chronically deceitful and distrust others. Though they typically exhibit remarkable charm, their relationships tend to be superficial because they are not capable of emotional intimacy and eschew commitment and reciprocity.

Cognitively, people with APD tend to be externally oriented and inflexible. They tend to be intelligent and skilled at reading social cues, people, and situations. However, their contempts of rules and authority, combined with a deep-seated sense of entitlement, allow them to rationalize and justify their aggressive and/or manipulative behavior.

From an emotional standpoint, their feelings could be described as shallow; a certain emotional "register" (warmth, tenderness, compassion, genuine love) is associated with weakness and kept at bay. The capacity for tolerating frustration and boredom is remarkably low. Guilt and shame are not part of their emotional experience.

An antisocial personality style shares some behavioral and emotional characteristics with APD, but it is certainly less malevolent and extreme in its manifestations. Like all personality continuums, at one end of the spectrum there are traits and tendencies mitigated by some self-regulatory or moderating factors; at the other, a deeply pathological organization of personality which pervades behavior, relationships, and emotional processing. For example, someone with an antisocial personality style may tend to live in the present and seldom feel guilt or regret while an individual with antisocial personality disorder may focus on instant gratification and feel justified in exploiting others without remorse. Similarly, an antisocial personality style can be associated with courage and boldness to the point of recklessness, but with antisocial personality disorder this often translates into disregard for anyone's safety, physical or emotional (Sperry, 1995).

From a relational standpoint, gaslighting is one of the hallmarks of antisocial personality disorder. In this form of psychological abuse, false or self-serving information is presented in such a way that the target doubts his/her own perceptions and memories. Similar to brainwashing, it can cause someone to gradually lose their sense of self as their view of reality is consistently called into question and understandable feelings and reactions are met with shaming and/or aggression. The target begins to feel uncertainty and unpredictability which are the norm and retreats into a defensive stance of distress and attempts to please or contain. The more confused and distraught the target becomes, the more the APD individual feels satisfaction and pleasure. Eventually, the aggressor loses interest and begins to further devalue and, finally, discard the victim (McGregor \& McGregor, 2013). APD individuals engage in manipulative or abusive cycles repetitively and compulsively in order to experience feelings of exhilaration and contempt (which has been termed contemptuous delight), only fueling his or her feeling of grandiosity (Birch, 2015). There is a marked lack of compassion; remorse and empathy are seen as vulnerability. Though there are narcissistic qualities, the APD individual sees himself as 
superior - there is no underlying inferiority complex (as is often observed with narcissists). His stance can best be described as predatory and self-involved to the point of malevolent grandiosity - life is a game and others are pawns meant to entertain him or be of use to him. Beyond this core state of pernicious narcissism, sense of self is weak: APD individuals are excellent shape-shifters and adapt to whatever behavior or attitude is self-serving in a given situation.

\section{Narcissistic Personality Disorder}

Narcissistic Personality Disorder involves a long-standing pattern of grandiosity or inflated self-image, a constant need for admiration, and poor empathy beginning in early adulthood and expressed in multiple areas. Deeply wrapped up in self-referential thinking, people with Narcissistic Personality disorder feel entitled and are scarcely aware of or concerned with the feelings and perspectives of those around them. They can be prone to interpersonally exploitative behavior. Oversensitive to criticism, they typically believe others are envious of $\mathrm{him} /$ her and take on arrogant behaviors and attitudes. Their inflated sense of self causes preoccupations with fantasies of hyperbolic success as well as a belief they deserve to associate with the best of the best and indeed can only be understood by high-status people or institutions. At the core, a narcissist knows he or she is special - empathy and intimacy are difficult because their sense of self is not permeable but rather fixed around a pervasive belief in their superiority.

From a behavioral standpoint, individuals with NPD usually appear boastful, self-centered, and domineering in conversation. They may act in a pompous or exhibitionistic manner, always seeking attention and admiration in an arrogant or even bossy fashion, or, at times, in an eccentric, larger-than-life show of entitlement. Their attitude can sometimes appear endearing and charming, but they can quickly become inpatient, insensitive, and prone to disdainful rage when faced with criticism. They may exploit others interpersonally to satisfy their own needs and feel entitled to do so in a very spontaneous manner since they are at the center of the universe. From a schema therapy standpoint, a person with Narcissistic Personality Disorder can be seen as operating within the impaired limits domain, which includes entitlement.

Cognitively, they tend to process their experience through themes and images rather than facts (Sperry, 1995). In an effort to presence their illusions of grandeur they are willing to twist the facts and justify any thought or belief in line with their exaggerated sense of self-importance.

Affectively, they typically behave in a nonchalant or even charmingly striking manner-unless they are challenged or they perceive their confidence or superiority is under attack. They are likely to respond with rageful, dramatic behavior or act like they are being victimized. Their relationships remain superficial insofar that they never allow anyone to "get under their skin", even by experiencing deep empathy and compassion.

\section{Borderline Personality Disorder: Relational Dynamics and Case Study 1}

Susanna (age 36) and Sam (age 42) came into my office seeking couples' therapy following a particularly dramatic fight which ended with a demonstrative suicide attempt on Susanna's part. Overwhelmed by years of intense, cyclical conflict, both partners declared they felt deeply attached to one another and did not want the relationship to end but felt exhausted and pessimistic about being able to change their dynamic. They explained that they went through "honeymoon "phases of total symbiosis, doing everything together and feelings "like one person"- - then, something would happen to precipitate conflict, leading to an explosive stage in which "things that should never be said or done happen", followed by a cooling period in which Susanna felt deep shame, insecurity and emptiness while Sam retreated into a feeling of impotence and detachment he associated with both relief and guilt. 
After the assessment phase, it became clear that Susanna suffered from Borderline Personality Disorder. While Sam certainly had some maladaptive defenses, his sense of self appeared to be quite solid. Susanna was raised by a single mother who became involved with several different partners. Each time she and Susanna would move into the man's home; the little girl would try to adapt to the new situation only to be uprooted again when her mother ended the relationship. Susanna found herself competing for her mother's attention and also faced unpleasant dynamics (i.e., one stepfather figure was unreliable and emotionally absent, leading Susanna's mother to be preoccupied, other-directed, and rely on her young daughter for comfort) and traumatic events (another stepfather figure sexually abused her from age ten to thirteen). During adolescence, Susanna developed self-injurious behavior (cutting) and bulimia. By age 25, she had attempted suicide (by ingesting excess medication) three times. In the current relationship, lasting for five years, she and Sam lived together and worked together (she was an administrative assistant at his large warehouse company). They spent a great deal of time together, though Sam desired some degree of independence (going out with male friends, pursuing his hobby of running marathons, spending time with his step-sister, a very significant affective figure for him). Susanna, on the other hand, became irrationally fearful and angry whenever Sam turned his attention to anything other than their relationship. This inevitably led to fights which usually took on the form of jealous raging and demonstrative self-injurious behavior on Susanna's part (getting drunk and staying out all night, cutting, blaming, raging, breaking objects, threatening suicide). In the cooling period, however, Susanna was plagued by shame and emptiness, and retreated into a state of subjugation associated with further relational turmoil. For example, Susanna (who presents as flirtatious and sexually provocative) normally interacts with male co-workers in a way that makes her feel powerful ("I can get them to do anything, I know how to play my cards"), but when she is experiencing shame and emptiness (after fighting with Sam), she experiences them as sexually threatening, yet is unable to contain unwanted behaviors by said co-workers (compliments, physical proximity) and also unable to ask for Sam's Support. Sam experiences this as lack of trust and he minimizes her experiences. The most recent fight, which precipitated their request for therapy, occurred when Susanna became rageful and jealous while Sam was helping to plan her step-sister's wedding. It culminated with Susanna accusing Sam of having sex with his own step-sister. Sam's reaction this time was uncharacteristically intense: he wrote her an email saying he could not go on this way, that she was "crazy" and that he was thinking about how much happier he would be on his own. After directing her rage and despair at Sam, Susanna ingested a large quantity of pills and sent a picture to Sam (who was temporarily staying at his mother's house for the weekend) with the caption "hope you're happy you killed me". Sam alerted emergency services and Susanna's life was saved, but these recent events left them both deeply shaken.

\section{Salient Themes in Therapeutic Intervention}

Susanna's volatile reactions with Sam are a result of her fragmented sense of self and the pervasiveness of splitting as a primitive defense. According to "object relations theory", their minds retain good representations separately from bad representations, creating two separated (split-off) representations of the same "other" rather than a single cohesive whole. Therefore, instead of understanding that their experience of a loved one has changed, they instead believe the person has changed and feel intensely threatened and/or hurt by perceived injury or disinterest. This polarized view of self and others is associated with extremes of perception (Hoermann, Zupanick, \& Dombeck, 2018). Therefore, facilitating awareness of this dynamic and fostering a more balanced processing of perception became a therapeutic priority. For Susanna, imagery work was extremely helpful. Mental rehearsal, anticipatory thinking, memories, and many other features of our minds entail the presence of mental imagery. Neuroscientific research indicates that mental images-including pre-experiencing (imagining/picturing a situation) and re-experiencing (memory) activate the same brain mechanisms as does physical experience (imagery can be used to recall, transform, visualize, re-route, re-assess, and more). Engaging with imagery can lead to insight, memory, and perception that is not accessible through verbal routes alone. An added benefit is that the client is encouraged to become open to imagination, flexibility, expression, and mentalization. This can even be modeled through language, by asking questions like "how do you picture that?", "where would you say you feel that in your body?", "if that were some sort of creature or alien, what would it look like?" (referred to emotion or other abstraction). Susanna was able to form a mental map which 
helped her navigate the splitting reaction. Together with Sam, she formed a core mental image she could associate with what, through couples processing, they could agree represented their core commitment and affection for one another. The image was one of the two of them rowing the same boat on a serene lake. Susanna practiced going back to this image and associating it with self-soothing during times of irrational fear that Sam was an enemy determined to abandon or destroy her. Next, she pictured her primordial fear and rage (which emerged when she felt threatened with abandonment or distancing) - she was able to identify it as thick black smoke that blinded her and made it difficult to breathe. Over time, she became skilled at mentally circumscribing this black cloud in a confined space in her solar plexus and not diffused everywhere inside and outside herself (as she had previously pictured it). Cognitively understanding splitting, combined with mastering these images, allowed her to face her overwhelming reactions as something she could have an effect on, instead of feeling overtaken by an external locus of control and deep despair.

Schemas are psychological constructs largely outside of conscious awareness that underlie our beliefs, identity, and emotional lenses. They are formed in childhood and adolescence and are repeatedly activated throughout the lifetime in a variety of relational and intrapsychic settings (including memories and anticipatory thinking). Maladaptive schemas can also be seen as self-defeating affective, behavioral and relational patterns sparked by deep-seated psychological wounds (Young, Klosko, \& Weishaar, 2006). When maladaptive schemas are activated, a person experiences an intense emotional, cognitive, and behavioral response known as a mode (Farrett et al., 2014). Modes are specific clusters of cognitions, feelings, and behaviors characterized by intense emotional arousal that are activated by internal stimuli (memories, anticipatory thinking) or external stimuli (interpersonal interactions, observed reality) and filtered through one's encoded schemas. Maladaptive coping modes are survival responses to trauma or unmet needs, including flight, fight, and freeze responses. They activate in connection with the person's schemas and incorporate his/her defenses. For example, Susanna often activated an abandonment/instability schema combined with a vulnerability to harm schema in a misguided unconscious effort to protect the vulnerable child from loss, uncertainty, and pain.

When maladaptive schemas are activated, a person experiences an intense emotional, cognitive, and behavioral response known as a mode. Modes are specific clusters of cognitions, feelings, and behaviors characterized by intense emotional arousal that are activated by internal stimuli (memories, anticipatory thinking) or external stimuli (interpersonal interactions, observed reality) and filtered through one's encoded schemas.

Susanna's early experiences caused her to internalize multiple dysfunctional parent and inner child modes, so it was important to address her core unmet needs and help her become conscious of how her interactions with others triggered deep reactions that were outside the scope of the here and now. 
Table 2

Client's Modes and Associated Features (Susanna)

\begin{tabular}{|l|l|l|l|}
\hline Mode type & Mode & Root & Key associated feelings/features \\
\hline Innate child & Vulnerable child & $\begin{array}{l}\text { Unmet attachment needs (incl. } \\
\text { safety, secure base, nurturance, } \\
\text { attention, protection, acceptance, } \\
\text { empathy, love) }\end{array}$ & $\begin{array}{l}\text { Sadness, loneliness, anxiety, } \\
\text { overwhelming pain and fear. Can } \\
\text { spill into maladaptive coping modes }\end{array}$ \\
\hline Innate child & Angry/Impulsive child & $\begin{array}{l}\text { Unmet needs for guidance, } \\
\text { validation of feelings and needs, } \\
\text { freedom to express self and feelings }\end{array}$ & $\begin{array}{l}\text { Venting, anger, explosive behavior, } \\
\text { "tantrum" like acting out }\end{array}$ \\
\hline Dysfunctional parent & Avoidant protector & $\begin{array}{l}\text { Caregiver has authority but is } \\
\text { emotionally unavailable, distant, or } \\
\text { unreasonable }\end{array}$ & $\begin{array}{l}\text { Pushes others away, lacks } \\
\text { spontaneity, breaks connections, } \\
\text { withdraws, isolates, and avoids }\end{array}$ \\
\hline Dysfunctional parent & Compliant surrenderer & $\begin{array}{l}\text { Caregiver is ineffective, damaged, } \\
\text { weak, or traumatized }\end{array}$ & $\begin{array}{l}\text { Surrenders to all schemas, acting as } \\
\text { if true. E.g.: if schema is } \\
\text { self-sacrificing, gives up own needs; } \\
\text { if it is defectiveness/shame, accepts } \\
\text { self as failure and does not try }\end{array}$ \\
\hline
\end{tabular}

Sources: Farrell et al., 2014.

From a schema therapy standpoint, a person with borderline personality disorder can be seen as operating within the impaired autonomy and performance domain, which includes various schemas that are activated within the relational dyad. The therapist facilitates understanding of how each partner's dynamics and triggers interact, especially in the domains of autonomy/dependence continuum, emotional regulation issues, "permitted" vs. "taboo" behaviors and emotions, and coping styles/ basic needs.

\section{Impaired Autonomy and Performance Domain}

Table 3

Client's Schemas and Corresponding Maladaptive Beliefs and Relational Dynamics (Susanna)

\begin{tabular}{|l|l|l|}
\hline Schema (Susanna) & $\begin{array}{l}\text { Maladaptive belief } \\
\text { (Susanna) }\end{array}$ & Relational dynamic \\
\hline Dependence/incompetence & $\begin{array}{l}\text { I am unable to handle } \\
\text { things without help }\end{array}$ & $\begin{array}{l}\text { Susanna is demanding, nagging, clinging-Sam feels suffocated, } \\
\text { resentful. }\end{array}$ \\
\hline Failure to achieve & $\begin{array}{l}\text { I am a loser now and will } \\
\text { always fail }\end{array}$ & $\begin{array}{l}\text { Susanna is periodically paralyzed by self-doubt and a sense of emptiness. } \\
\text { Sam feels helpless and angry when rationalizing with her does no good. }\end{array}$ \\
\hline Subjugation & $\begin{array}{l}\text { I must comply with others } \\
\text { or face adverse } \\
\text { consequences }\end{array}$ & $\begin{array}{l}\text { At work, Susanna is unable to contain unwanted behavior of co-workers } \\
\text { but also unable to ask for Sam's Support. Sam experiences this as lack of } \\
\text { trust and he minimizes her experiences. }\end{array}$ \\
\hline Abandonment/instability & $\begin{array}{l}\text { Sam will leave me and I } \\
\text { will be destroyed } \\
\text { irreversibly }\end{array}$ & $\begin{array}{l}\text { Susanna is irrationally jealous, suspicious accusatory, and fearful } \\
\text { whenever Sam takes any space from the relationship. She reacts volatily } \\
\text { and dramatically. Sam alternates between angry defensiveness and } \\
\text { anxiety/feelings of suffocation/non-verbalized resentment. }\end{array}$ \\
\hline Enmeshment & $\begin{array}{l}\text { I must constantly be at the } \\
\text { forefront of Sam's life or } \\
\text { this relationship is doomed }\end{array}$ & $\begin{array}{l}\text { Susanna clings to Sam and sabotages his independent initiatives and } \\
\text { relationships. Sam begins to be deceitful and, over time, feels helpless and } \\
\text { guilty as well as resentful. }\end{array}$ \\
\hline Vulnerability to harm & $\begin{array}{l}\text { Terrible things are going to } \\
\text { happen no matter what I do }\end{array}$ & $\begin{array}{l}\text { Susanna projects her deep anxiety onto most situations, becoming } \\
\text { dramatic and hyperbolic - expecting Sam to contain her emotions and } \\
\text { absorb them. Sam first expends energy to accommodate/reassure her; } \\
\text { eventually he retreats into a self-induced indifference he also feels guilty } \\
\text { about (leading to reduction of emotional intimacy). }\end{array}$ \\
\hline
\end{tabular}

This conceptualization helped us focus on and address specific dynamics which led to conflict in the dyad. 
Splitting and loss of control were addressed so that dramatic conflict in the pair bond was reduced.

\section{Narcissistic Personality Disorder: Relational Dynamics and Case Study 2}

Jane (age 25) initially came into therapy stating she had a "food addiction" and was feeling depressed. Having recently graduated from university, she had not yet found a job was living with her mother Sissy (age 51). Jane complained of feeling worthless, lonely, unable to find direction. She had over-achieved academically and felt she was now a "failure" in her current situation. She described feeling guilty about having disappointed her mother, who was a classical pianist of some success. I conducted a full assessment focusing on attachment and schemas. At third session, without forewarning, Jane arrived with her mother, insisting she could "help her explain". Sissy announced "this is so hard for me. I worked so hard and now having a daughter like this—-how do you think I feel?" When I inquired about what she meant, she looked at Jane and quipped "well, like a hog in heels!" Jane did not seem angered by this; rather, she began to justify how she was getting help for being "weak with food". It became clear through therapeutic work that Sissy had begun exhibiting a pattern of grandiosity and self-referential thinking early in life. Her daughter was viewed as a failed extension of herself-she verbally expressed concern and distress for Jane's situation, but perceived everything in a self-referential manner. There was a great deal of underlying anger directed at Jane; her daughter's academic achievements were underplayed and attention focused on how she "made her look". Sissy reported Jane had been a "wonderful child" but had "lost her way". Early on, Jane had attuned herself to her mother's overwhelming needs, introjecting her anxiety and doing everything in her power to please and unburden her. As she grew, however, her dawning autonomy caused Sissy to become increasingly verbally abusive and guilt-inducing, whilst projecting a grandiose, almost heroic image of herself unto the outside world. Jane's emotional needs were not met—indeed, she was routinely shamed for them and made to feel they caused her mother suffering, exhaustion and embarrassment. Her hurtful behavior was usually turned around in a way that made her appear victimized - for example, she would undermine or insult Jane and say "sorry you're so sensitive" or "sorry you don't appreciate having an honest mother, after all I've done for you". I was able to eventually direct Sissy to a separate therapist (she declined) and continue work with Jane. Schema therapy helped her identify her internalized working models, her damaged sense of self, and her maladaptive coping styles. She was able to recognize the affects her relationship with her narcissistic mother had on her and begin working in earnest on herself as a separate individual deserving of her own perceptions, desires and needs.

\section{Salient Themes in Therapeutic Intervention}

Just as individuals with Antisocial Personality Disorder, narcissists are prone to gaslighting. In their case, however, manipulation for pleasure is not the underlying motivation; rather, gaslighting becomes instrumental to maintaining a grandiose view of self. Because they are so deeply self-centered, rather than taking the perspectives and needs of others into consideration, they will endeavor to conform the perceptions of loved ones to their own views. Thus, people in close contacts with a narcissist may begin to doubt their own sense of reality and unconsciously retreat into a space where their needs and perceptions are secondary (or even irrelevant) compared to the narcissist's. Jane was exhibiting signs of long-standing traumatic bonding with her mother. We drew from a combination of cognitive restructuring and schema work to help her sort her own identity, needs, and wishes from her narcissistic mother's, repairing her capacity for independently interpreting inner and outer states without feeling guilt and shame for doing so without looking at the world through her mother's emotional lens.

Insecure avoidant attachment develops when a caregiver is physically and emotionally unresponsive the child's needs. This is typically seen in relationship dyads marked by neglect. The child learns that he/she has no power to influence the external world or to engage others and that expressing his/her needs is a pointless, frustrating exercise. These children may become passive, depressed, and even developmentally delayed. They learn that acknowledging or displaying distress may lead to punishment, rejection, or disappointment and become accustomed to self-soothing/self-nurturing behaviors which can sometimes translate into proneness to 
maladaptive or addiction-based behaviors. These children may exhibit a world view of "pseudo independence" wherein they consciously believe they are self-reliant but are in fact deeply preoccupied with unmet needs and a sense of lack of control. Jane was able to understand how her attachment to Sissy had affected her sense of self; she formulated goals and worked on healthier self-soothing (instead of overeating) and finding situations and relationships that maximized her potential/inner resources instead of fueling her sense of powerlessness and intrinsic defectiveness.

Table 4

Client's Modes and Associated Features (Jane)

\begin{tabular}{|l|l|l|l|}
\hline Mode type & Mode & Root & Key associated feelings/features \\
\hline Dysfunctional parent & Demanding parent & $\begin{array}{l}\text { Unrealistic demands and standards, } \\
\text { disregard for child's individual } \\
\text { wishes and needs, projection }\end{array}$ & $\begin{array}{l}\text { Sets exceedingly high expectations } \\
\text { for self, pressures self, has a harsh, } \\
\text { negative, shame-based stance towards } \\
\text { self, dissatisfied, fears failure }\end{array}$ \\
\hline Innate child & Vulnerable child & $\begin{array}{l}\text { Unmet attachment needs (incl. } \\
\text { safety, secure base, nurturance, } \\
\text { attention, protection, acceptance, } \\
\text { empathy, love) }\end{array}$ & $\begin{array}{l}\text { Sadness, loneliness, anxiety, } \\
\text { overwhelming pain and fear. Can } \\
\text { spill into maladaptive coping modes } \\
\text { and addiction }\end{array}$ \\
\hline
\end{tabular}

From a schema standpoint, Jane took stock of her internalized dysfunctional parent and vulnerable child and we worked on repairing these inner working models by nurturing a healthy adult mode characterized by independence, self-awareness, boundaries, and permission to develop intimate relationships.

\section{Antisocial Personality Disorder: Relational Dynamics and Case Study 3}

James (age 19) was court mandated to go into therapy as part of a juvenile rehabilitation program he had started at age 17. Because he was a minor at the time he committed his crimes and stood trial for them, the legal system allowed him an opportunity to keep a clean record by following a 24 month program which included permanence in a monitored group home, psychological care, volunteering, attending a skill-building course in screen printing and regular checkups by social services. Once he turned 18, he was able to leave the group home and return to his parents' home while still continuing to follow the rest of the program. The court forwarded his file, which contained his history and official statements made by his parents, cousin, ex teachers at various points in time. James had been a hyperactive child, boisterous and both mischievous and charming. By age 8, however, he began getting into fights in school and by 12 he had been caught shoplifting several times. Around this time he also was involved in an incident with two older kids that caused alarm for his parents and the whole town: they hung a dog on the edge of a nearby pine forest. By age 14, James had developed a steady pattern of bullying, fighting and stealing. At home, he refused to follow rules and often became enraged or leave without permission and stay out the whole night. Although he was highly intelligent, his school attendance began to suffer as he often skipped school and hung around older kids, smoking, drinking and breaking into cars to steal whatever they could find. He also stole from the family home, his grandmother's house (he took jewelry with sentimental value and pawned it) and his school. At home, he would often behave in a spiteful, cruel manner. He was particularly inclined to bully his younger sister, four years his junior. He routinely broke her belongings and filmed her reaction on his cell phone. On one occasion, he twisted her arm behind her and told her to play a game to see how long she could last without screaming - this actually caused the little girl to fracture her wrist. He would constantly play "games" meant to elicit shock, anger, or discomfort in his immediate family. For example, pour vinegar or salt in whatever his mother was cooking to render it inedible and then say he was "just kidding". He taunted his father about having had a mild heart attack, calling him "half assed". At age 17, he and an older friend stole a minivan, broke into their school and stole several computers, and went driving and drinking until they caused a hit-and-run accident that nearly cost a young couple their lives. After this spree, he was arrested and mandated to undergo the 24 month program. After leaving the group home and returning to his parents', James seemed to be keeping a low profile. During intake, he struck me as well-spoken, extroverted and relaxed. He stated he was glad to be home and enjoying more freedom, insisting he felt happy and "just bored". He attempted to ask me several questions and complimented me on my pendant, my desk lamp, my "friendliness". After 
several sessions, we began making references to his juvenile record and early experiences. James' demeanor changed. While discussing his present he distanced himself from any rageful or ill-spirited feelings; when answering questions about his past, he would first express he "wasn't like that anymore" and "used to be immature". After this caveat, he would become more soft-spoken, almost seductive as he recounted more and more incidents, in increasing detail and unsolicited precision. It was soon evident that he took great pleasure in discussing his criminal acts, and especially the reactions (shock, pain, shame, fear) he got from his "games" with people. As I attempted to set limits and pointed out that he seemed to be quite invested in trying to shock others - perhaps myself included, he became genuinely angry. Gone were the compliments and smiles - now I was "dumb" for "thinking I could know what he thought". Over time, James often made comments about me "putting words in his mouth", denied things he had stated only minutes early, and attempted to ask me personal questions. When I asked him questions or made observations he felt threatened by, he would typically fall silent for several seconds and then make some sort of cryptic statement such as "oh, sorry, I was just thinking about how easy it is to cut the breaks on someone's car" or shocking proclamation "I think my little sister is a little slut". It was not possible to engage him in any meaningful schema work, as he alternatively indulged or mocked anything that was said. We started focusing on basic cognitive behavioral techniques after he agreed that "thinking more sharply" could be of interest to him. He insisted every example or concept specifically tie back to how he could outsmart or "convince" others to do what he wanted. My attempts at re-directing work towards his own inner mechanisms and maladaptive thinking were met with resistance. He seemed to be most comfortable making statements that he expected me to disapprove or limit. It was no longer just about past actions; he would tell me he was cheating on his girlfriend with a number of girls; he discussed having fake profiles on social media to "make things interesting" and described pitting people against each other or framing acquaintances for cheating. He once told me he "missed his chance to bang Emma" (his sister) when he was still a minor. When he failed to elicit the desired reactions in me, he would devalue me and attempt to discuss my personal life. Therapy was discontinued when he was arrested — this time as an adult — after being accused of sexually and physically assaulting a young woman in his parents' neighborhood.

\section{Salient Themes in Therapeutic Intervention}

The therapy relationship was exemplary of Antisocial Personality Disorder dynamics_-James was eager to shock, outsmart, and domineer. He used manipulative and gaslighting tactics meant to make me question my memory and understanding of his statements. When challenged, there were displays of covert aggression (making dramatic, vaguely menacing statements) and attempts to divert attention through shocking remarks. Both his stories, told in increasing, unsolicited detail, and his cognitive and emotional demeanor made it quite plain that he derived pleasure and satisfaction in trying to elicit intense, distressing emotions in others (fear, shock, shame, pain). James displayed remarkable resistance to personal insight, insisting in trying to twist any input meant to modify or question his own maladaptive behavior into nothing more than information he could master in order to outsmart other people. His well-spoken intelligence was striking and charming, and, at first , he behaved in a complimentary, idealizing manner. As he tested my reaction to his increasingly psychological and physically violent stories, I confronted him with my observation that he seemed to be quite invested in trying to shock others - perhaps myself included. He became genuinely angry and antagonistic. Gone were the compliments and smiles - now I was "dumb" for "thinking I could know what he thought". From then on, his resistance to alliance and empathy was expressed through contempt, attempts at baiting and denying, and vilification of any vulnerability.

Gabbard (2014) argues that identification is most apparent in treatment when the psychopathic patient attributes certain negative characteristics to the clinician and then attempts to control the clinician, perhaps through overt or covert intimidation. James endeavored to do this by making ominous, covert threats and by attempting to direct attention towards my personal life and character. The therapeutic relational dynamic centered around the theme of control. 


\section{Conclusion}

Disordered personality functioning profoundly affects areas of identity, self-direction empathy, and intimacy. Because personality disorders are, by definition, pervasive and influence perception, behavior, thinking, and emotional processing, they inevitably have a profound effect on the person's close relationships. This work focuses on three Cluster B personality disorders (Borderline, Narcissistic, and Antisocial Personality Disorder), specifically illustrating how relational dysfunction manifests in each condition.

This work examines aspects of Borderline, Antisocial, and Narcissistic Personality Disorder, discussing themes of self-image and relational dynamics. Case Study 1 presented a case of a couple with the female partner suffering from borderline personality disorder. Relational dynamics characterized by her maladaptive schemas and coping mechanisms were unstable, volatile, and dramatic. There was a cyclical dynamic of symbiotic demand $\rightarrow$ jealous rage at any perceived threat $\rightarrow$ explosive conflict with self-harm by Susanna $\rightarrow$ cooling phase marked by shame, emptiness (hers) and distancing inducing guilt/relief (his) $\rightarrow$ new perceived threat of abandonment. Through attachment and schema work, splitting and loss of control were addressed so that dramatic conflict in the pair bond was reduced.

Case Study 2 involved a young woman with a narcissistic mother. The daughter complained of food addiction, depression, and feelings of worthlessness; her narcissistic mother attempted to overtake the therapeutic process. It was evident that the young woman's relational experience with her entitled, grandiose, shaming, gaslighting parent had a profound effect on her sense of self and efficacy. Schema work helped her identify and process internalized working models of vulnerable child and dysfunctional parent and she was able to move towards emotional independence.

Case Study 3 described a young man exhibiting antisocial personality disorder. He had a long history of dishonest, violent and reckless behavior, and a pervasive attraction for causing distressing feeling-states in others. He was court-ordered to be in therapy, and the therapeutic relationship became quite exemplary of the APD relational dynamic. He played out a psychopathic pattern: charming/seducing $\rightarrow$ gaslighting/controlling $\rightarrow$ devaluing, resisted personal insight, and sought pleasure in efforts to elicit shock and distress. His acceptance of intervention was limited to cognitive notions he felt he could master and later use to outsmart others; attempts at empathic alliance were met with contempt and baiting/denying; interventions apt to modify/question his maladaptive behavior led to covert aggression.

Clearly, interpersonal dynamics are profoundly affected by disordered personality organization. An analysis of and intervention upon the relational sphere these individuals operate in can be therapeutically beneficial and conceptually illuminating.

\section{References}

Birch, A. (2015). Psychopaths and love. Online edition consulted via Kindle.

Esbec, E., \& Echeburúa, E. (2015). The hybrid model for the classification of personality disorders in DSM-5: A critical analysis. Psiquiatr, 43(5), 177-186.

Gabbard, G. O. (2014). Gabbard's treatments of psychiatric disorders (5th ed.). M. D. Gabbard, (Ed.). Washington, D.C.: Amer Psychiatric Pub.

Hoermann, S., Zupanick, C. E., \& Dombeck, M. (2018). The dimension of personality organization. Retrieved from https://www.researchgate.net/scientific-contributions

Kernberg, O. F. (2001). Borderline personality disorder: A psychostructural nosology. In International encyclopedia of the social \& behavioral sciences (pp. 1285-1290). Amsterdam, Netherlands: Elsevier. 
McGregor, J., \& McGregor, T. (2013). The empathy trap: Understanding antisocial personalities. London: SPCK: Sheldon Press. Oldham, J. (2015). The alternative DSM-5 model for personality disorders. World Psychiatry, 14(2), 234-236.

Sperry, L. (1995). Handbook of diagnosis and treatment of the DSM-IV personality disorders. Levittown, PA: Brunner/Matzel.

Thomas, K., Yalch, M. M., Krueger, R., Wright, A., \& Hopwood, J. (3 September 2012). The convergent structure of DSM-5 personality trait facets and five-factor model trait domains. Assessment. doi:10.1177/1073191112457589

Trull, T., \& Widiger, T. (2013). Dimensional models of personality: The five-factor model and the DSM-5. Dialogues ClinNeurosci, 15(2), 135-146.

Young, J. E., Klosko, J. S., \& Weishaar, M. E. (2006). Schema Therapy: a Practitioner's Guide. New York, NY: The Guilford Press. 